\title{
Everything You Always Wanted to Know About Being Postdigital but Were Afraid to Ask a Vampire Squid
}

\author{
Tyson E. Lewis ${ }^{1}$
}

Published online: 29 October 2019

(C) Springer Nature Switzerland AG 2019

In 2010, my co-author, Richard Kahn, and I coined the term exo-pedagogy to refer to a particular kind of 'teaching' out of bounds of the traditional parameters denoting the field of humanist educational discourse and practice (Lewis and Kahn 2010). Our starting point was an observation concerning the inherent human-centric focus of educational philosophy. We argued that Western education must assume a gap between human and non-human animals as a starting point in order to transform the human into a citizen subject. This gap was not natural but rather an artifact of the anthropological machine underwriting the educational project writ large. But what if we started elsewhere, in those monstrous moments of mixture and contamination that always interrupt the smooth workings of this educational project, reminding us that the cut separating hand from hoof is never so clear, precise, or stable as one might want it to be? Instead of anthropocentrism, we opted for zoomorphism as a founding principle for exo-pedagogic experimentation. Notice how -centrism is replaced with -morphism in this formulation, as a dispersion of forms that are permanently and infinitely variable, lacking any sense of originary purity. The result of this experiment in thinking education out of bounds was a posthuman practice of zoomorphic imaginings, close encounters with UFOthers, the curation of curricular cabinets of curiosity, and feral methodologies for conducting educational research in the hinterlands of culture and science. Education as bestiary, education as monstrous. These were the central aims of our inquiry.

Today, it would seem that the postdigital is also interested in a similar set of phenomena. Instead of assuming as a starting point a dichotomy between analog and digital educational forms of life, it assumes that they are always already plugged into one another: a flesh electric. Whereas our original formulation of exo-pedagogy proposed monsters that combined traits of the human and the animal, here we find the same formulation but in relation to inorganic machines, codes, and screens. The cybernaught — rather than the reptoid, the hydra, or faery - thus takes center stage as the postdigital monster par excellence.

Tyson E. Lewis

Tyson.Lewis@unt.edu

1 University of North Texas, Denton, USA 
But perhaps we can bring these two projects into orbit with one another and suggest the following hypothesis: all that one needs to know about a postdigital experience is already found in the lifeworld of the vampire squid. In a surprising twist, authors Flusser and Bec (2012) argue that as humanity becomes more and more entwined with postdigital forms of life, we become increasingly squid-like. One of the defining features of squids is their chromatophoric skin which gives outward expression to the inner life of the organism. They are literally living screens, characterized by a 'volatile immanence' (Flusser and Bec 2012: 51) where inside and outside, surface and depth, public and private divisions no longer hold true. Squid culture is a sophisticated culture of image production on a biological screen that is their skin. Human 'software processing' can be read as a reference to 'soft animals' such as mollusks whose flesh is composed of pixels (chromatophores) and whose cultural labor is the production of affective images (rather than material goods). The squid therefore finds itself on the threshold of the digital, and the human finds itself on the threshold of the cephalopod. Flusser and Bec (2012: 67) summarize, 'We [humans] are vertebrates of such complexity that we managed to appropriate, by developing an immaterial art, an evolutionary strategy of mollusks.'

If this is indeed the case, then we can also pinpoint the particular ethics of a postdigital exo-pedagogy through an encounter with vampire squids. As Flusser and Bec point out, the vampire cybernaught must confront the violence, orgiastic surplus, and culture of deceit of the vampyroteuthis that is now very much our own culture. To do so means to invent new kinds of postdigital, diabolical fables that enable us to acknowledge the other in ourselves and ourselves in others across any purported digital or species divide in such a way that the uncanny space of mirroring produces joyous encounters rather than merely destructive ones.

\section{References}

Flusser, V., \& Bec, L. (2012). Vampyroteuthis infernalis: a treatise. Minneapolis: University of Minnesota Press.

Lewis, T. E., \& Kahn, R. (2010). Education out of bounds: reimagining cultural studies for a posthuman age. New York: Palgrave Macmillan. 